\title{
$\mathrm{PH} \mathbf{1 0 2} \boldsymbol{2}_{\text {seate }}$
}

a debate Comunicación y redes sociales en instituciones culturales

| coordina Candela González Sánchez

\section{Una red de museos en las redes sociales: Nuestros Museos}

Rocío del Pozo Sánchez, Laura Fernández Frutos | Subdirección General de Museos Estatales, Ministerio de Cultura y Deporte

URL de la contribución <www.iaph.es/revistaph/index.php/revistaph/article/view/4818>

El Ministerio de Cultura y Deporte gestiona de forma directa dieciséis museos adscritos a la Dirección General de Bellas Artes a través de la Subdirección General de Museos Estatales, unidad administrativa que coordina y da apoyo a su trabajo en distintos campos.

Estos museos ${ }^{1}$ tienen personalidad y voz propia pero, a su vez, forman parte de una marca común que los agrupa: Nuestros Museos. Es a través de Nuestros Museos como se vertebra y comunica el trabajo común de estas instituciones. Dicha comunicación se realiza por diferentes vías: web, mailing, redes sociales... En el caso de las redes, Nuestros Museos está presente en Twitter y Facebook, gestionadas por un equipo que tomó las riendas a finales del 2019 y que trabaja de forma cooperativa y coordinada junto con el resto de personas dedicadas a la comunicación dentro del Área de Difusión y Desarrollo. Este cambio de equipo se vio reforzado por el enorme peso que adquirió la comunicación digital desde marzo de 2020 con el inicio de la pandemia por la COVID-19. Así, durante los meses de marzo, abril y mayo, con los museos cerrados, al igual que otras tantas instituciones culturales, la comunicación digital y las redes sociales se convirtieron en la única cara de la moneda que podía ver el público. El museo continuaba con su trabajo de puertas para adentro, pero al no existir actividad presencial, todo se volvió virtual y las instituciones se identificaron más que nunca por su actividad en las redes.

No obstante, y a pesar del enorme impulso motivado por la virtualización de la vida social y cultural derivada de la pandemia, no podemos considerar a las redes sociales nuevas instituciones de la cultura por sí mismas, aunque sí podemos afirmar que son una de las voces con las que se expresan estas instituciones, concretamente, una voz que se ha vuelto la más versátil y útil para proyectar nuevos objetivos y llegar a nuevos públicos.

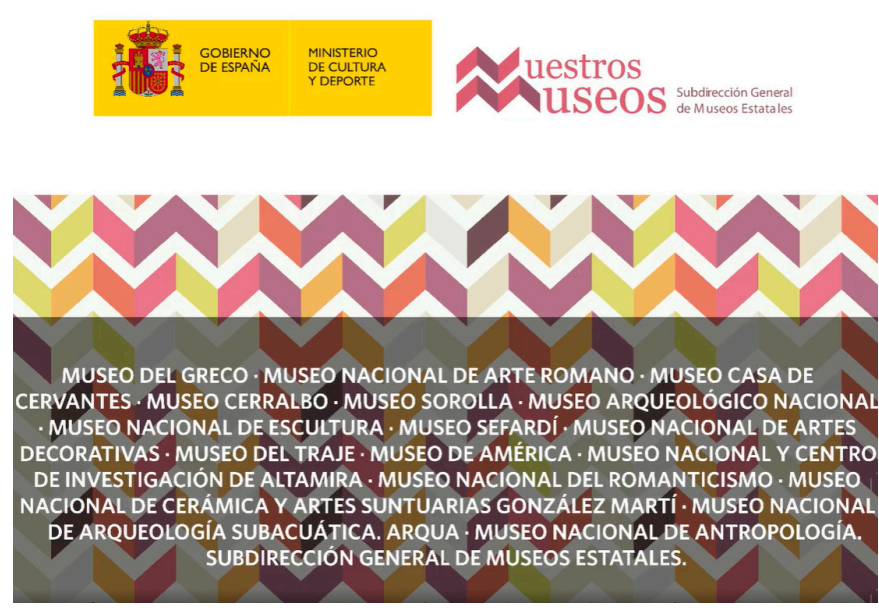

Fotograma del vídeo de agradecimiento a profesionales realizado en abril del 2020

En base a esos objetivos, las estrategias de comunicación de Nuestros Museos se concretan en cuatro ejes bien definidos que reflejan su actividad, con la particularidad de tratarse de la comunicación de una red de museos:

> Por una parte, la comunicación de acciones conjuntas en las que participa parte o la totalidad de los museos, que se unen en torno a fechas clave como el Día Internacional de los Museos o la Museum Week para organizar iniciativas comunes.

$>$ Nuestros Museos tienen además conexiones internas unos con otros basadas en sus colecciones, la historia particular de algunas piezas, su arquitectura o su origen histórico. Las redes nos permiten visibilizar estos lazos a través hilos de Twitter o citas entre museos.

$>$ Otro punto clave es el refuerzo de la comunicación de los museos como instituciones individuales. La comunidad creada en torno a cada perfil es distinta y, a través 
de Nuestros Museos, se puede lograr un "intercambio" de públicos, ampliando las comunidades receptoras y pudiendo llegar, cada uno de los museos que forman la red, a otro tipo de públicos.

> Por otra parte, otra de las líneas de comunicación versa sobre los proyectos desarrollados desde servicios centrales del Ministerio, la Subdirección General de Museos Estatales, donde se trabaja en proyectos como el Observatorio Iberoamericano de Museos, el Observatorio de Museos de España o el Laboratorio Permanente de Público de Museos, tejiendo redes profesionales con museos de distintos entornos.

Precisamente la concepción de la cultura como un servicio público que redunda en beneficio de la ciudadanía, intrínseca a nuestras instituciones, elimina de nuestro planteamiento comunicativo el enfoque comercial. Si bien buscamos hacernos más visibles, llegar a más personas con medios y fines cada vez de mayor calidad, nuestro objetivo siempre presente es el de enriquecer las formas de mirar, sumar y unir. A todo esto cabe añadir que la contratación de publicidad no suele ser una opción viable para los museos públicos, por lo que la comunidad o comunidades que se conforman en las redes sociales son una vía importante para trabajar por esos objetivos y la creatividad se convierte, por tanto, en una herramienta fundamental.

De hecho, durante la pandemia quedó reflejado que la ciudadanía acudía a las instituciones culturales para mantenerse conectada, unida. En un momento en el que la realidad cercenaba posibilidades y caminos, las redes y la comunicación digital entendieron la necesidad y reaccionaron para dar más contenido y de mayor calidad y actuar también como vía de escape, entretenimiento y deleite, algo que sólo se pudo conseguir mediante comunicación creativa. La nueva situación y la demanda del público aceleró el ritmo y fomentó sinergias y nuevas formas de trabajar que han redundado en la creatividad y la originalidad como las mejores herramientas de trabajo, que a su vez han permitido el crecimiento de estas redes en un 72 y $17 \%$ respectivamente en 2020 .
En definitiva, en este equilibrio rico y dinámico, la identidad individual de cada museo se ve reforzada en la comunidad de museos a la que pertenece, destacándose al mismo tiempo los aspectos que hacen único a cada uno, con los que lo vinculan a una comunidad de instituciones y usuarios.

\section{NOTAS}

1. Museo Nacional de Arqueología Subacuática, ARQUA; Museo Arqueológico Nacional; Museo Cerralbo; Museo de América; Museo del Traje, CIPE; Museo Nacional de Antropología; Museo Nacional de Artes Decorativas; Museo Nacional del Romanticismo; Museo Sorolla; Museo Nacional de Arte Romano; Museo Nacional y Centro de Investigación de Altamira; Museo del Greco; Museo Sefardí; Museo Nacional de Cerámica y Artes Suntuarias "González Martí"; Museo Casa Cervantes y Museo Nacional de Escultura.

\section{BIBLIOGRAFÍA}

- Ministerio de Cultura y Deporte (2020a) ¿Cómo comunicamos? Las redes sociales y los museos a debate. I Encuentro Día Internacional de las Redes Sociales. Disponible en: http://www.man.es/man/actividades/actividadesextraordinarias/historico-extraordinarias/2020/20200630-diainternacional-redes-sociales.html [Consulta: 16/12/2020]

- Ministerio de Cultura y Deporte (2020b) Encuentro virtual: ¿Cómo comunicamos? las redes sociales y los museos a debate. II Encuentro Día Internacional de las Redes Sociales. Disponible en: https://www.culturaydeporte.gob.es/mgreco/ actividades/conferencias/encuentrovirtual.html [Consulta: 16/12/2020]

- Usillos Gutiérrez, A. (2020) Enredándonos en las redes. Sala de reflexión. Antropología para momentos críticos. Disponible en: http://www.culturaydeporte.gob.es/dam/jcr:ce1efe0a-77cd48d0-9a88-b72b96d3bc4d/andre-s-gutie-rrez-enredados-enlas-redes.pdf [Consulta: 08/12/2020] 